\title{
Assessment of Turbulent CFD against STS-128 Hypersonic Flight Data
}

\author{
William A. Wood* and William L. Kleb* \\ NASA Langley Research Center, Hampton, Virginia, 23681 \\ Andrew J. Hyatt ${ }^{\dagger}$ \\ ELORET Corporation, Sunnyvale, California, 94086
}

\begin{abstract}
Turbulent CFD simulations are compared against surface temperature measurements of the space shuttle orbiter windward tiles at reentry flight conditions. Algebraic turbulence models are used within both the LAURA and DPLR CFD codes. The flight data are from temperature measurements obtained by seven thermocouples during the STS-128 mission (September 2009). The flight data indicate boundary layer transition onset over the Mach number range 13.5-15.5, depending upon the location on the vehicle. But the boundary layer flow appeared to be transitional down through Mach 12, based upon the flight data and CFD trends. At Mach 9 the simulations match the flight data on average within $20^{\circ} \mathrm{F} / 11^{\circ} \mathrm{C}$, where typical surface temperatures were approximately $1600^{\circ} \mathrm{F} / 870^{\circ} \mathrm{C}$.
\end{abstract}

\section{Nomenclature}

$h \quad$ Altitude, $\mathrm{km}$

$M \quad$ Mach number

$M_{t r} \quad$ Mach number at transition onset

T Temperature, $\mathrm{F}$

$\alpha \quad$ Angle of attack, degrees

$\beta \quad$ Sideslip angle, degrees

Acronyms

CFD Computational fluid dynamics

DPLR Data-parallel line relaxation CFD code

LAURA Langley aerothermodynamic upwind relaxation algorithm CFD code

OML Outer mold line

RCC Reinforced carbon-carbon

RCG Reaction cured glass

STS Space transportation system

TC Thermocouple

\section{Introduction}

BOUndary layer transition experiment ${ }^{1}$ was conducted on the space shuttle orbiter Discovery during A the STS-128 reentry in September 2009. The experiment included a 0.35-inch tall boundary layer trip installed in the thermal protection tiles on the windward side of the port wing, catalytic coatings on two tiles downstream of the trip, and nine thermocouples to measure surface temperatures in the vicinity of the trip.

*Aerothermodynamics Branch, senior AIAA member.

${ }^{\dagger}$ Research Scientist, AIAA member. 


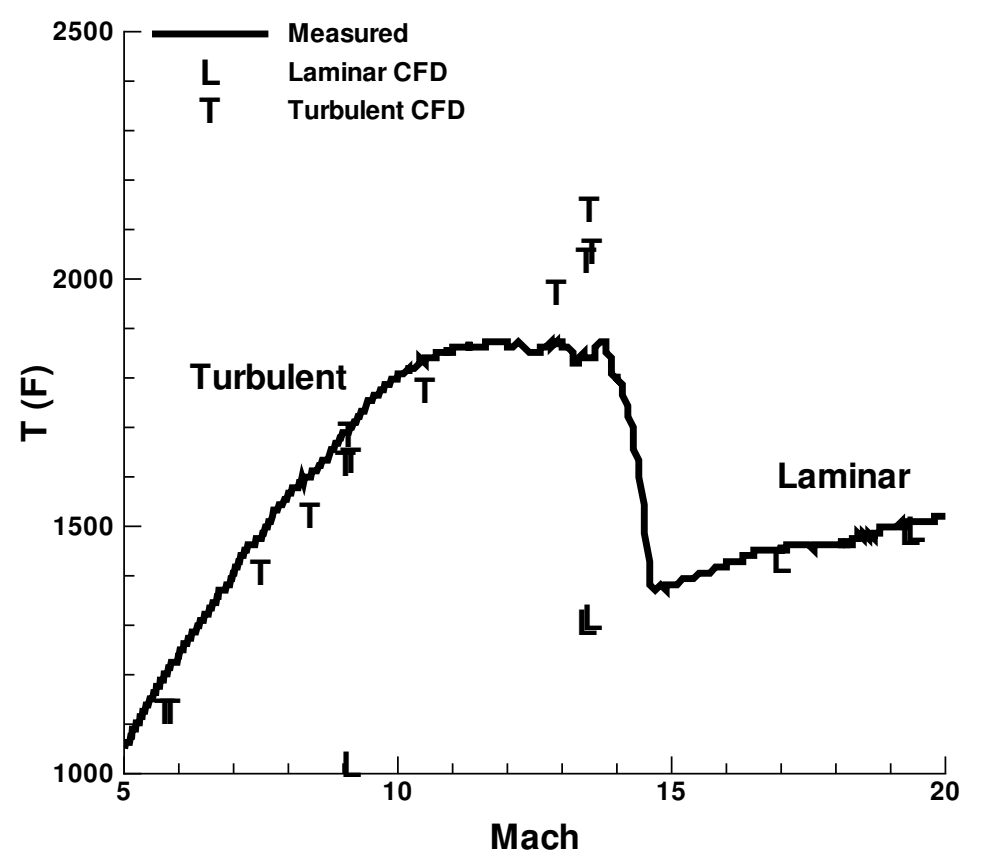

Figure 1. Turbulent CFD trend diverging from STS-119 flight data for $M>11$. Plot data taken from Figure 8(a) in reference 2. Trace is flight data; $\circ$ are LAURA CFD; $\times$ is DPLR CFD.

Seven additional thermocouples measured windward surface temperatures as part of the standard vehicle instrumentation system. As interpreted from the thermocouple time histories, ${ }^{1}$ the trip caused boundary layer transition on the port wing starting at Mach 17.5, registered by a thermocouple embedded in one of the tiles with a catalytic coating. The earliest indication of boundary layer transition on a non-coated tile in the wake of the flight experiment protuberance was at Mach 15.5. The port windward acreage transitioned at Mach 13.6 due to an unidentified source on the forward portion of the fuselage. The starboard acreage transitioned at Mach 8.5. The present assessment is for attached windward turbulent flow over the thermal protection tiles, and the thermocouple measurements for tripped boundary layer flow range from Mach 15 and below.

A similar boundary layer transition experiment had been previously conducted during the STS-119 reentry. The trip for that experiment was shorter, 0.25 inches, and boundary layer transition initiated at a lower Mach number, 15.5. Measurements from four thermocouples located in the wake of the experiment trip indicated transitional or turbulent flow at Mach numbers above 11. Two assessments of turbulent CFD predictive capability have been presented and showed similar results for algebraic, one-equation, and two-equation turbulence models. ${ }^{2,3}$ The qualitative and quantitative CFD agreement with the flight data were good for Mach numbers below 11, but the CFD temperature trends diverged from the measurements for Mach numbers greater than 11. A typical comparison from reference 2 is reproduced in Figure 1, plotting temperature versus reentry Mach number. The trace is the measured OML temperature from a thermocouple ${ }^{\mathrm{a}}$ downstream of the boundary layer trip, and the symbols represent various laminar and turbulent CFD simulations. The measured temperatures show a plateau above Mach 11, but the CFD simulations predict a roughly linear increase in turbulent surface temperatures with increasing Mach number.

The STS-128 flight experiment offered an opportunity for more insight into this temperature plateau seen in the STS-119 flight data, which was not reflected in the CFD predictions. In comparison to the STS119 flight data, STS-128 had: more thermocouples in tripped boundary layer at Mach numbers above 11, boundary layer transition at a higher Mach number due to the taller flight experiment trip, and acreage transition at an earlier Mach number due to the aforementioned unidentified source forward of the wings. The aim of the present report is to perform a similar assessment of CFD turbulence modeling against the STS-128 flight data as was performed for the STS-119 data. In particular, is a similar divergence in surface temperature trends between simulation and measurement seen at high Mach numbers; and if so, is the break

\footnotetext{
${ }^{a}$ The particular STS-119 thermocouple shown in Figure 1 is V07T9758A. This thermocouple was not present on STS-128.
} 


\begin{tabular}{llrl} 
Full name & Short name & $M_{t r}$ & Note \\
\hline V07T9752A & TC-2 & 15.5 & Downstream of trip. \\
V07T9754A & TC-4 & 13.6 & Downstream of trip. \\
V07T9756A & TC-6 & 14.0 & Downstream of trip. \\
V07T9757A & TC-7 & 13.6 & Downstream of trip. \\
V07T9647A & TC-8a & 13.6 & Downstream of trip. \\
V07T9480A & TC-80 & 13.6 & Port mid-fuselage. \\
V07T9590A & TC-90 & 13.6 & Aft centerline. \\
V07T9751A & TC-1 & 17.5 & Catalytic coating on tile. \\
V07T9646A & TC-3a & 17.4 & Catalytic coating on tile. \\
V07T9755A & TC-5 & 14.2 & Close to trip. \\
V07T9929A & TC-9 & 13.6 & On boundary layer trip. \\
V07T9711A & TC-11 & 13.6 & Port wing tip. \\
V07T9730A & TC-30 & 13.9 & On elevon. \\
V07T9666A & TC-66 & 13.6 & Wing leading edge. \\
V07T9468A & TC-68 & 8.3 & Lower Mach number transition. \\
V07T9597A & TC-97 & 8.5 & Lower Mach number transition.
\end{tabular}

Table 1. Thermocouple names and locations. The bottom group (beginning with TC-1) was not used for the present assessment. Transition Mach numbers are taken from reference 1.

point at Mach 11 or does it increase with increasing transition-onset Mach number?

The present report employs the two CFD codes LAURA and DPLR. Two algebraic turbulence models, Baldwin-Lomax and Cebeci-Smith, are used in the CFD codes to model turbulent boundary layers. Windward OML temperatures at the thermocouple locations are used as the metric of engineering interest for the assessment of the turbulent CFD simulations over a 9-15 Mach number range.

\section{Flight data}

Flight data are available for 16 thermocouples on the windward side of Discovery from the STS-128 reentry. ${ }^{1}$ The thermocouple names are listed in Table 1 . The overall layout of the thermocouples on the orbiter is shown in Figure 2, and a close-up view in the vicinity of the flight experiment is shown in Figure 3, which has been taken directly from Figure 15 in reference 1.

The thermocouples were installed in the orbiter thermal protection tiles, just under the tile RCG coating. The outside of the RCG coating constitutes the vehicle OML. Reference 1 estimates the temperature drop between the OML and the thermocouple installation point as approximately $20^{\circ} \mathrm{F}\left(11^{\circ} \mathrm{C}\right)$. Therefore, all raw thermocouple temperatures have been raised by $20^{\circ} \mathrm{F}$ (less than a $1 \%$ correction) for comparison with CFD predictions of the OML temperature. The thermocouple precision uncertainty is estimated at $\pm 20^{\circ} \mathrm{F}$ in reference 1. The space shuttle orbiter program has traditionally reported thermocouple measurements in Fahrenheit; for consistency with the existing body of literature, Fahrenheit is used in the present report.

The thermocouple temperature histories presented here all follow the template of Figure 4, which plots temperature versus Mach number. TC-80 and TC-97 are shown; these thermocouples are located symmetrically to the port and starboard at $60 \%$ of the vehicle length. The reentry trajectory traverses the Mach number domain monotonically from high to low, with the portion from Mach 20 to Mach 5 plotted. The temperature range is scaled to accomodate all the thermocouple measurements, remaining constant across the plots to aid comparisons. The temperature trends associated with the higher Mach numbers are indicative of laminar flow, whereas the temperature trends associated with the lower Mach numbers are indicative of turbulent flow; the boundary layer flow is assumed to be transitional during the rise from laminar to turbulent temperature levels. Reference 1 states the transition onset times for the two thermocouples: Mach 13.6 for TC-80 and Mach 8.5 for TC-97.

The time lag in temperature response of an orbiter tile-surface thermocouple due to the rapid increase 


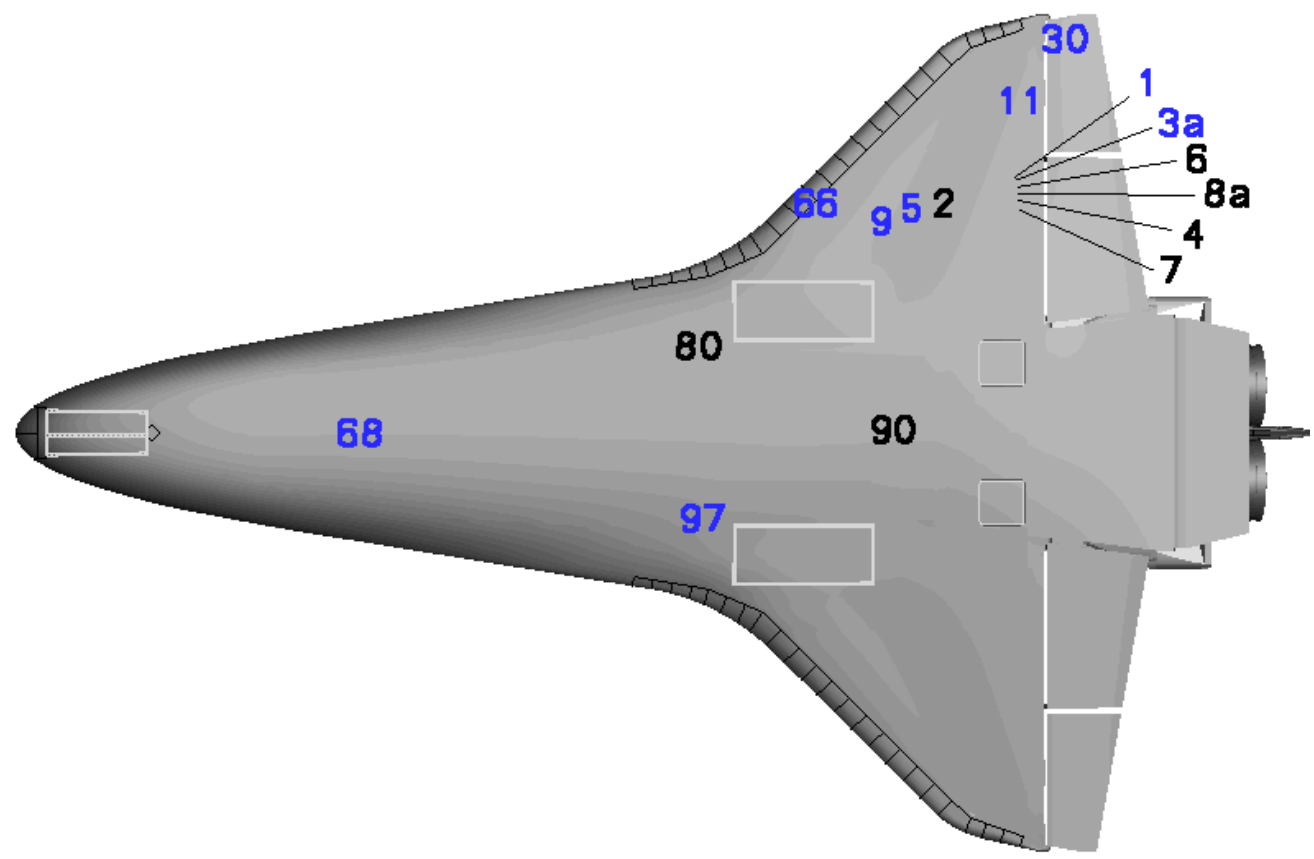

Figure 2. STS-128 thermocouple layout on Discovery, windward view. TC-9 is at the location of the flight experiment boundary layer trip. Blue text denotes thermocouples that were not used for the present assessment.

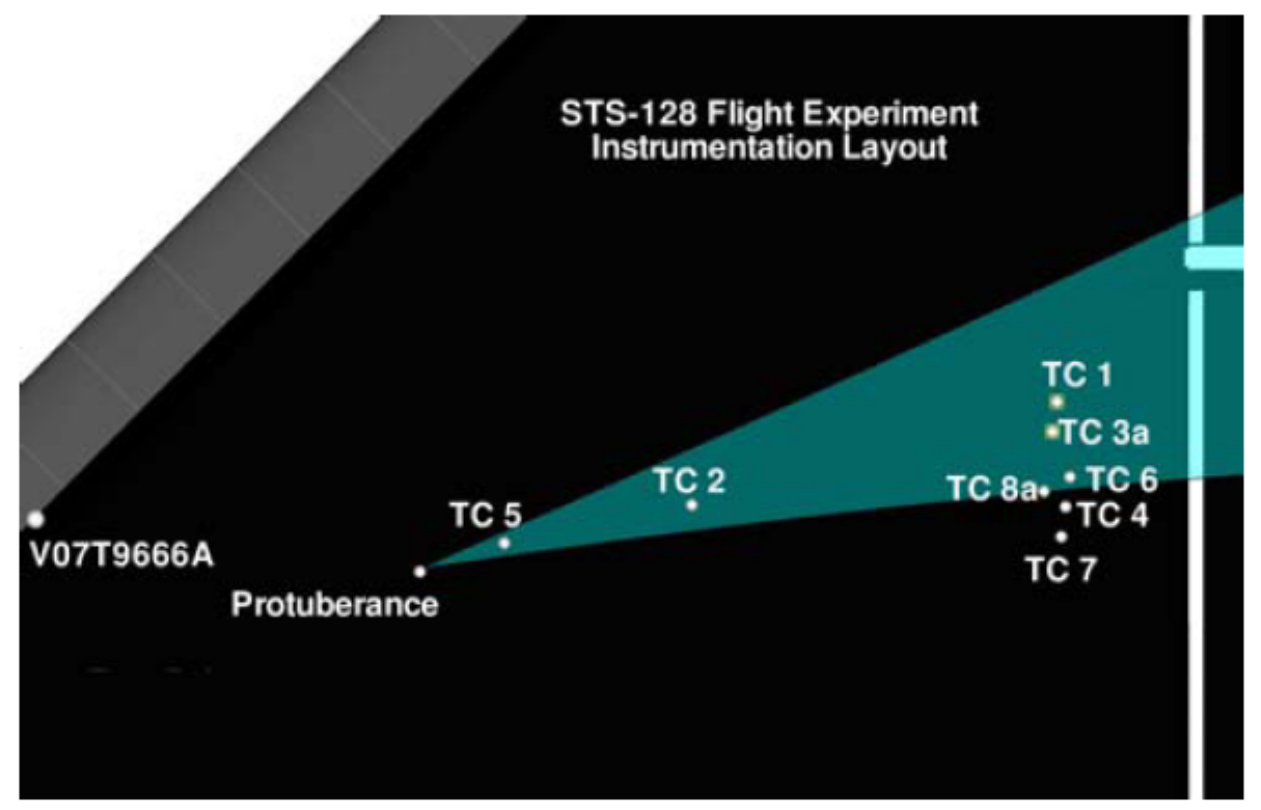

Figure 3. Thermocouple layout in the vicinity of the flight experiment. (This image is a duplication of Figure 15 in reference 1.) 


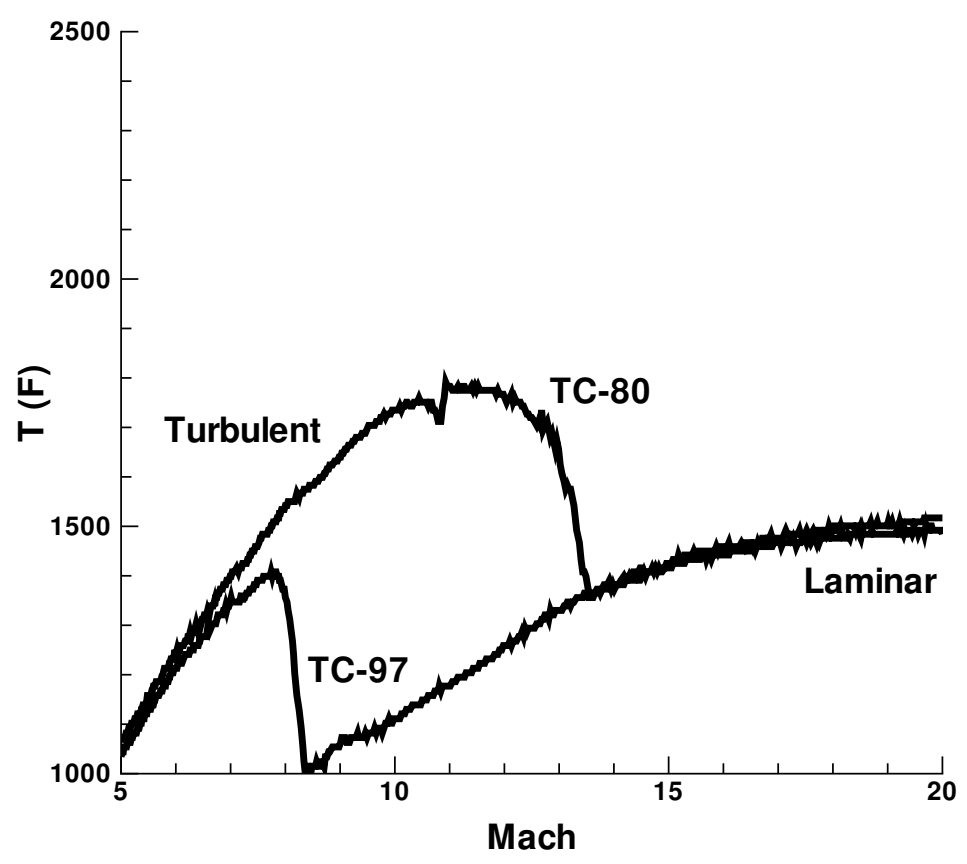

Figure 4. TC-80 and TC-97 temperature histories.

in convective heat transfer characteristic of boundary layer transition has been studied by Throckmorton. ${ }^{4}$ Using the STS-1 flight data, Throckmorton reports a time lag of about one minute for the thermocouple to reach radiative equilibrium temperatures after boundary layer transition onset. This time lag corresponds to a drop in Mach number of approximately two increments. Because of a recorder malfunction, STS-1 data was only available for Mach numbers below 11. TC-97 in Figure 4 does follow the trend observed by Throckmorton, where transition onset is at about Mach 8.5, and the TC-97 temperature asymptotes to the TC-80 temperatures at about Mach 6.5. In contrast, TC- 80 is not characteristic of the data observed by Throckmorton because the temperature does not rise to sharp peak after transition, but to a rounded peak. This difference in character of the temperature history after boundary layer transition onset at higher Mach numbers could be due to a longer period of transitional boundary layer flow, to a difference in the turbulent boundary layer profiles, or to a difference in the heat-soak behavior of the thermal protection tiles at this earlier point in the trajectory.

For the comparisons in section IV only seven of the sixteen thermocouples were used to assess the turbulent CFD capability. The nine thermocouples that were not used were omitted for these following reasons. The catalytic coatings on the tiles for TC- 1 and TC-3a were not modeled in the CFD geometry. The flight experiment protuberance (TC-9) was not discretely modeled in the CFD geometry. TC-5 was located in close proximity, about $20 \mathrm{in} . / 0.5 \mathrm{~m}$ downstream, to the flight experiment protuberance and TC-5's heating was significantly influenced by the protuberance even during the laminar portion of the flight. TC-30 was located on an elevon, and the elevon deflections were not modeled in the CFD geometry. The TC-11 temperature history exhibits atypical variations of hundreds of degrees; the proper operation of this sensor is in question. TC-66 was located on the wing leading edge at the RCC to RCG junction, a material properties junction not modeled by the CFD. TC-68 and TC-97 experienced boundary layer transition at lower Mach numbers than is the focus of the present assessment.

\section{CFD simulations}

The computational codes and methodology follows the practices described in reference 2. Based upon the close agreement between the results of the numerical codes in reference 2, code-overlap is performed for only one case in the present work. 


\begin{tabular}{rccr} 
Mach & $h, \mathrm{~km}$ & $\alpha,^{\circ}$ & \multicolumn{1}{c}{$\beta,^{\circ}$} \\
\hline 16.03 & 59.8 & 40.2 & 0.1 \\
14.75 & 58.2 & 42.0 & 0.0 \\
13.50 & 55.9 & 41.0 & -0.3 \\
12.02 & 54.2 & 40.1 & -0.4 \\
9.01 & 49.0 & 38.3 & -0.3
\end{tabular}

Table 2. STS-128 trajectory points. Flight sideslip angles are listed, but all CFD simulations set $\beta=0$.

\section{A. Codes}

The Langley Aerothermodynamic Upwind Relaxation Algorithm (LAURA) ${ }^{5,6}$ and the Data Parallel LineRelaxation (DPLR) software ${ }^{7}$ are both second-order accurate upwind finite-volume viscous-flow CFD solvers for use with block-structured grids. Air is modeled as five-species $\left(\mathrm{N}_{2}, \mathrm{O}_{2}, \mathrm{~N}, \mathrm{O}\right.$, and NO) in chemical nonequilibrium with thermal equilibrium. The entire vehicle surface is modeled with reaction cured glass (RCG) catalysis. ${ }^{8}$ Surface temperatures are modeled in radiative equilibrium with the convective heat transfer rates based on a uniform emissivity of 0.89 .

The simulations have either fully-laminar or fully-turbulent boundary layers. Turbulent simulations are fully-turbulent from the nose, wet the entire vehicle, and use the steady-state Reynolds-averaged NavierStokes equations. With LAURA, the algebraic Cebeci-Smith turbulence model is employed. With DPLR, the algebraic Baldwin-Lomax turbulence model is employed.

Previous laminar simulations of orbiter reentry flow fields, using the same CFD codes, have been reported in the context of the Columbia Accident Investigation ${ }^{9}$ and the subsequent Return-to-Flight program. ${ }^{10}$ During Return-to-Flight, laminar comparisons to Mach-18 flight data from STS-2 showed surface temperature predictions from LAURA to average $2.7 \%$ low with a $2.7 \%$ standard deviation; the DPLR surface temperatures averaged $0.6 \%$ low with a $3.2 \%$ standard deviation. Other applications of these codes to the orbiter vehicle have been reported, ${ }^{11-13}$ and additional context of the windward laminar flow field is available in the literature. ${ }^{14}$

\section{B. Cases}

The five STS-128 trajectory points listed in Table 2 were considered. The free stream conditions were obtained from the post-flight reconstructed trajectory, with the exception of sideslip; all CFD simulations set $\beta=0$ to benefit from the computational efficiency afforded by a plane of symmetry. Turbulent LAURA simulations were performed for all trajectory points. A turbulent DPLR simulation was performed for the Mach 9 point. A laminar LAURA simulation was performed for the Mach 14.75 point, in anticipation of future comparisons to global imagery data collected during STS- 128 by the HYTHIRM team, ${ }^{15}$ and is included with the present results for context.

The computational volume grids contain about 12 million cells, and are solution-adapted for bow-shock alignment and boundary-layer clustering. Simplifications were made to the aft end of the vehicle, resulting in the windward plan-form shown in Figure 5. The elevons are undeflected, the elevon gaps are not modeled, the body flap is omitted, and the trailing edge of the elevons has been extended to meet the body-flap truncation. The main engine and orbital maneuvering nozzles are omitted. The flow-field domain encompasses the bow shock and ends at the wing trailing edge. The OML is smooth, in that geometry perturbations smaller than a few inches are quilted over. In particular, the boundary layer trip on the wing is not discretely modeled in the CFD geometry; see Tang ${ }^{16}$ for CFD modeling of the boundary layer trip and vicinity flow field. The RCC structures are not distinctly modeled. Some of these differences can be seen by contrasting Figure 5 with Figure 2.

\section{Verification}

The current CFD solution process followed best-practices established during the space shuttle Return-toFlight program. ${ }^{10}$ In reference 10, quadrupling the computational grid tangentially to the surface decreased 


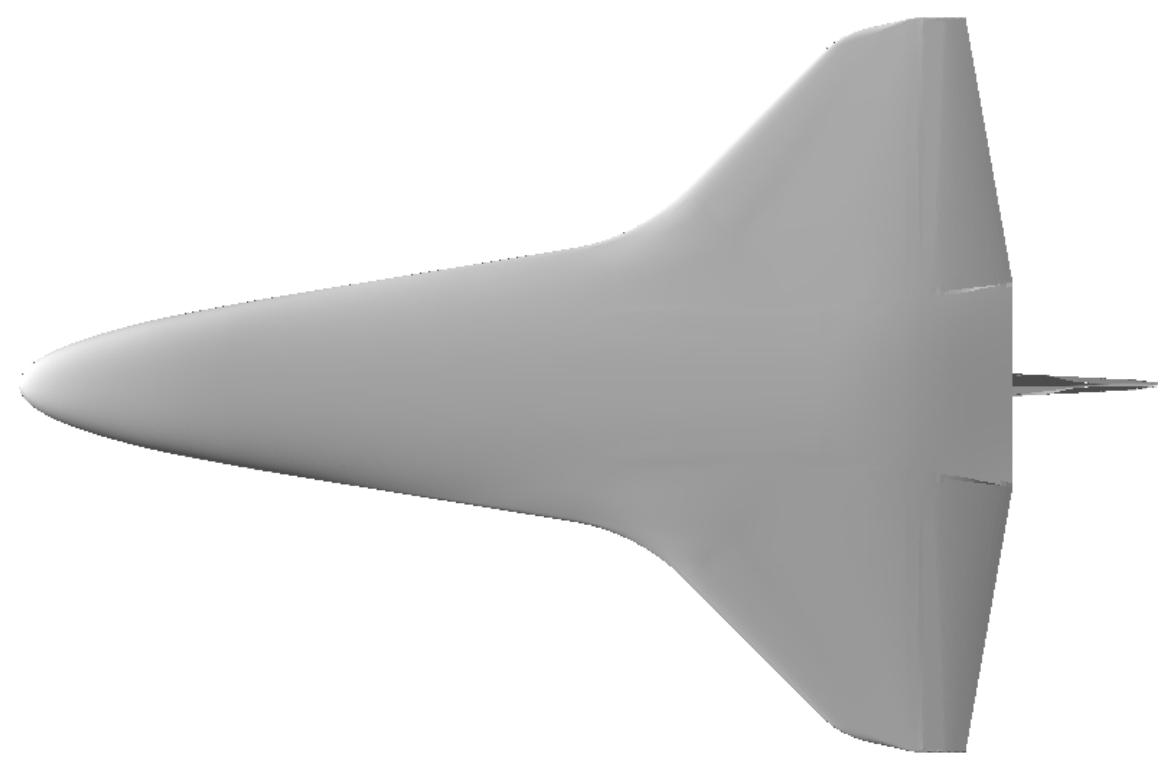

Figure 5. Windward planform of CFD vehicle geometry. Primary omission is the body flap.

the computed surface temperatures by $0.06 \%$ on average. Doubling the computational grid in the surfaceperpendicular direction decreased the computed surface temperatures by $1.11 \%$ on average.

In reference 2, a partial verification of the chemistry models was performed by repeating Mach-6 laminar and turbulent cases with both five-species and perfect gas air. The differences in heating rates, sampled at 11 thermocouple locations, were all less than $0.03 \%$ between the perfect-gas and five-species air models, for both laminar and turbulent simulations at Mach 6 . Surface temperatures were indistinguishable between the perfect-gas and five-species results.

Code-to-code comparisons between DPLR and LAURA were also performed at four laminar and three turbulent overlap points in reference 2. Predictions from both codes agreed very closely. In the present work the Mach 9 conditions were repeated with LAURA and DPLR, again with close agreement as detailed in section IV.

\section{Results}

Surface temperatures for the seven comparison thermocouples are plotted versus Mach number, along with the CFD predictions, in Figures 6-10. In the plots, the grouping of five higher-temperature CFD data points are from turbulent simulations and the lone lower-temperature point at Mach 14.75 is from the laminar simulation. Following the plots, the ensemble accuracy of the CFD predictions is presented.

The temperature history for thermocouple TC-2 is shown in Figure 6. This thermocouple was located approximately $60 \mathrm{in} . / 1.5 \mathrm{~m}$ downstream of the flight experiment boundary layer trip. The thermocouple begins to exhibit a ragged response starting at Mach 16.5, and indicates boundary layer transition at approximately Mach 15.5, as interpreted from the rapid rise in temperature, in this case of approximately $600^{\circ} \mathrm{F}$. The ragged response during the transition period is difficult to interpret, and could be due to the trip intermittently transitioning the flow at the limit of the trip's effectiveness, to the boundary layer not being fully turbulent, or the turbulent wake of the trip might have washed back and forth over the thermocouple despite the attempt to install TC-2 directly downstream of the trip, or there may have been another cause that is not understood. The peak measured temperature is $1927^{\circ} \mathrm{F}$. Because TC-2 experienced boundary layer transition onset at Mach 15.5, the laminar CFD simulation at Mach 14.75 is not appropriate for comparison with this thermocouple. The Mach-9 turbulent CFD prediction closely matches the measurement. The turbulent CFD predictions for Mach 12-15 all over-predict the measurement. These turbulent CFD predictions appear to match an extrapolation of the measured heating trend from $M<11$. The measured temperatures have a different trend for $M>11$, remaining roughly constant between Mach 11-15. The elapsed flight time between Mach 15 and Mach 11 was 122 seconds, and the Reynolds number increased by $50 \%$ between those 


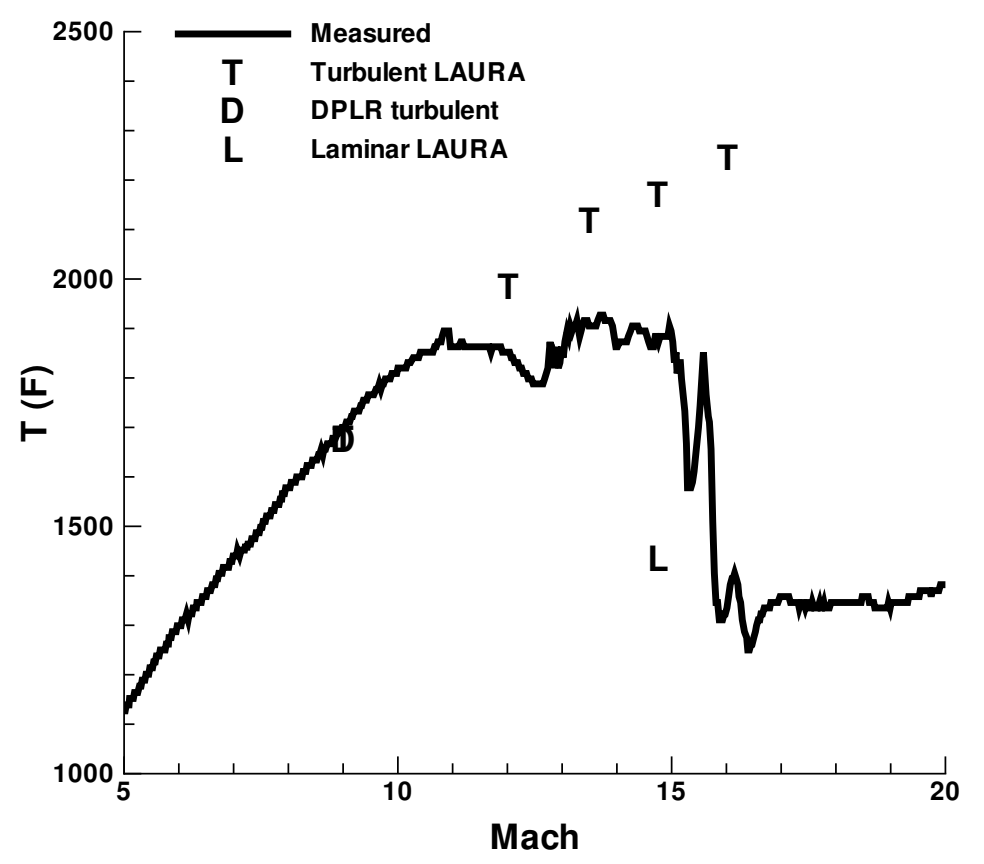

Figure 6. TC-2 temperature history.

Mach numbers, from 3.6 million to 5.4 million.

The temperature history for thermocouple TC-6 is shown in Figure 7. This thermocouple was located about 150 in./3.8 $\mathrm{m}$ downstream of the flight experiment trip, but not directly downstream. The placement of this thermocouple was intended to help characterize the spreading of the wedge of turbulent flow emanating from the trip. The temperature history begins to indicate transitional flow at about Mach 15 . The transitional response is not as ragged as for TC-2, and the rise in temperature from the laminar level is not as great, about $400^{\circ} \mathrm{F}$. The peak measured temperature was $1852^{\circ} \mathrm{F}$. Similarly to TC-2, the laminar CFD point is not appropriate for comparison with this thermocouple, and the Mach-9 turbulent CFD prediction is close to the measured value. The CFD predicted temperatures again rise with increasing Mach number, roughly extrapolating the $M<11$ flight data. In contrast, the measured temperatures are roughly constant over Mach 11-13. As compared to the TC-2 history, the TC-6 behavior, as well as the behavior of the remaining thermocouples to be discussed, is more smoothly varying, suggesting that the temperature 'plateau' may be a coincidental combination of extended temporal and spatial periods of transitional flow, the tile transient thermal response, and the vehicle deceleration during this portion of the trajectory.

The temperature histories for TC-4, TC-7, and TC-8a are all shown in Figure 8. These three thermocouples were all located in close proximity to one another, downstream of the flight experiment trip and inboard of TC-6. The measurements from all three thermocouples closely replicate one another. Boundary layer transition can be inferred at about Mach 13.5, most likely due to a surface irregularity, which was not identified in the post-flight vehicle inspection, located forward on the vehicle. A surface irregularity is suspected of having tripped the boundary layer upstream because TCs 4, 7, 8a, 80, and 90 all indicated boundary layer transition onset at the same time. For TC-7, the peak measurement was $1852^{\circ} \mathrm{F}$. The laminar CFD temperatures under-predict the flight data, but the Mach-9 turbulent CFD temperatures closely match the flight data. The higher-Mach-number turbulent CFD predictions again follow an extrapolation of the $M<11$ flight data. The thermocouple temperatures do not exhibit a distinct plateau.

The temperature history for TC-80 is shown in Figure 9. This thermocouple was located just forward of the port main landing gear door. Boundary layer transition began at about Mach 13.5. The laminar CFD prediction at Mach 14.75 under-predicts the flight measurement, and the turbulent CFD prediction at Mach 9 slightly under-predicts the measurement. The measured temperatures were still rising as the vehicle passed through Mach 12, indicating that fully-established turbulent surface temperatures had not yet been reached at that time. The thermocouple response peaks at Mach 11 , with a reading of $1791^{\circ} \mathrm{F}$, but the 


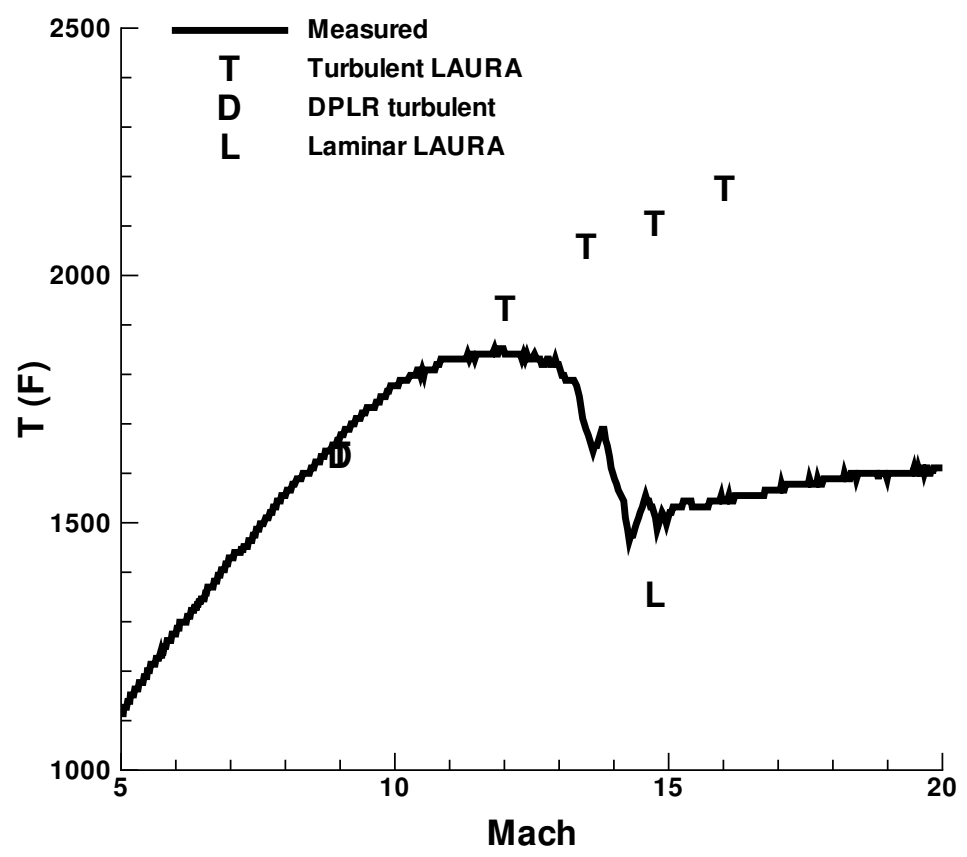

Figure 7. TC-6 temperature history.

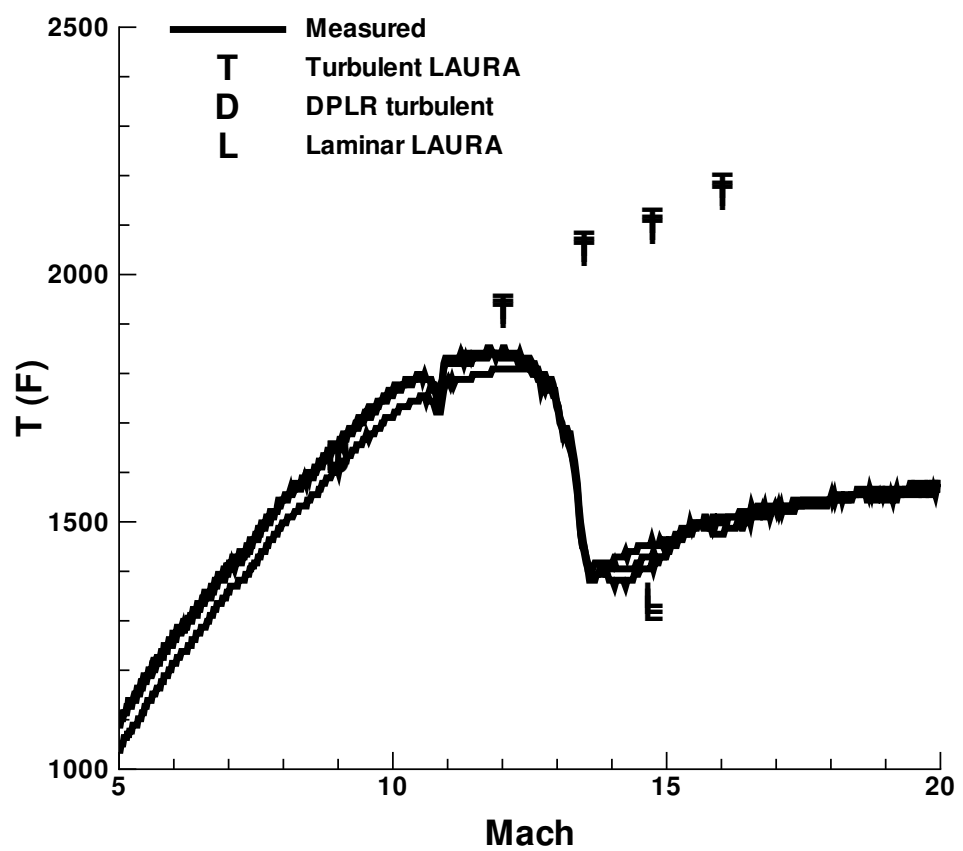

Figure 8. TC-4, TC-7, and TC-8a temperature histories. 


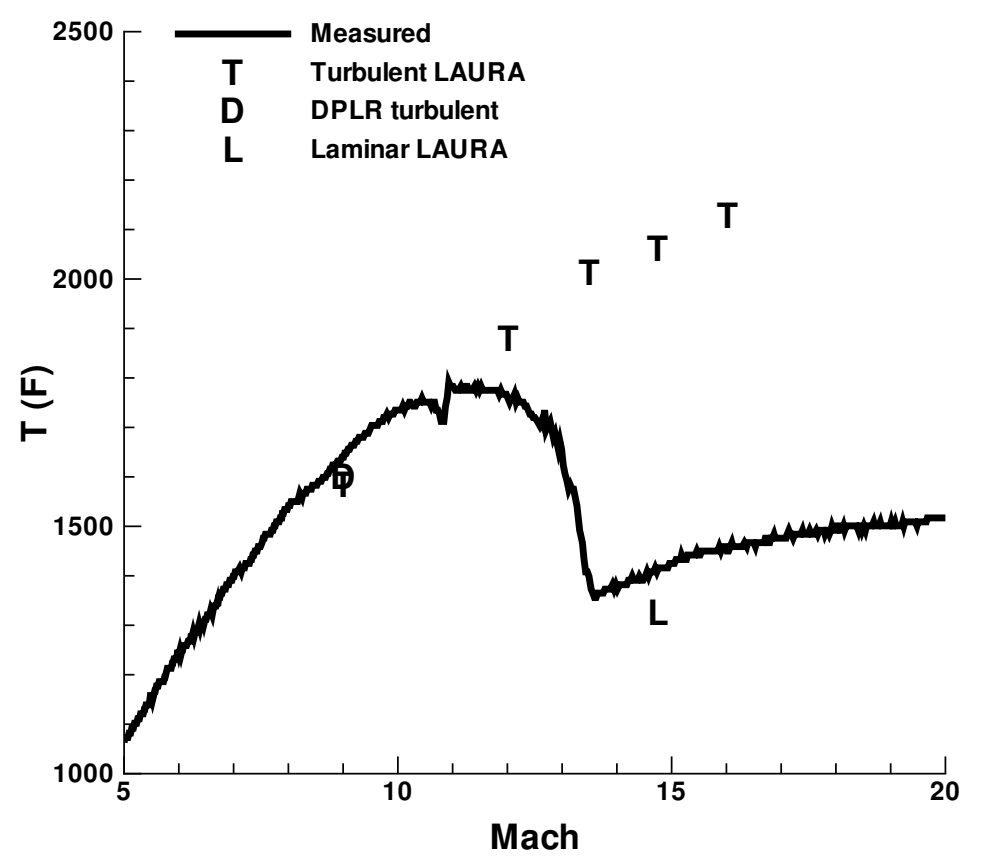

Figure 9. TC-80 temperature history.

response might still be in the laminar-to-turbulent transient phase at Mach 11.

The temperature history for TC-90 is shown in Figure 10. This thermocouple was located on centerline at about $75 \%$ of the vehicle length. Boundary layer transition began at about Mach 13.5. The peak recorded temperature was $1775^{\circ} \mathrm{F}$. The laminar CFD prediction slightly under-predicts the flight measurement at Mach 14.75. The Mach-9 turbulent CFD prediction matches the flight measurement. The response of TC-90 does not show a temperature plateau.

All seven thermocouples considered here indicated fully-developed turbulent conditions at the Mach-9 trajectory point. Fully-turbulent CFD simulations were performed with both LAURA and DPLR at Mach 9 as a verification check. The LAURA predictions averaged $20^{\circ} \mathrm{F}$ lower than the seven thermocouple readings versus $15^{\circ} \mathrm{F}$ lower for the DPLR predictions, with a $32^{\circ} \mathrm{F}$ standard deviation for the LAURA predictions versus a $33^{\circ} \mathrm{F}$ standard deviation for the DPLR predictions. Typical surface temperatures at Mach 9 were approximately $1600^{\circ} \mathrm{F} / 870^{\circ} \mathrm{C}$. For context, the reported precision uncertainty in the thermocouple readings is $20^{\circ} \mathrm{F}$.

For the Mach-12 trajectory point, the turbulent CFD predictions averaged $103^{\circ} \mathrm{F}$ higher than the flight measurements, with a $24^{\circ} \mathrm{F}$ standard deviation. TC-2 was the only thermocouple showing a sustained temperature plateau after boundary layer transition onset, but it is not clear from the flight data when the boundary layer had fully developed turbulent flow at the TC-2 location. The other six thermocouples either did not exhibit a post-transition temperature plateau or had a smoother temperature history than TC-2. A further investigation of the transient in-depth thermal response of the tiles is warranted to determine how much the CFD assumption of radiative equilibrium surface temperatures contributes to the CFD overprediction for the Mach-12 comparisons. In other words, additional reduction of the flight data into heat transfer rates might well allow for a more direct comparison with the present CFD results at Mach 12 by eliminating tile heat soak time lag.

Laminar surface temperatures were indicated at Mach 14.75 for thermocouples TC-4, TC-7, TC-8a, TC80, and TC-90. Compared to these five thermocouples, the laminar CFD predictions averaged $85^{\circ} \mathrm{F}$ low, with a $37^{\circ} \mathrm{F}$ standard deviation. This level of laminar CFD accuracy matches the results of reference 2 for a comparison to the STS-119 flight data.

Returning to the context of the previous turbulent CFD assessment against the STS-119 flight data, ${ }^{2}$ the present comparisons show that the STS-119 results were not an aberration. For both the STS-119 and STS-128 reentries the turbulent CFD predictions agree with the flight surface temperature trends for Mach 


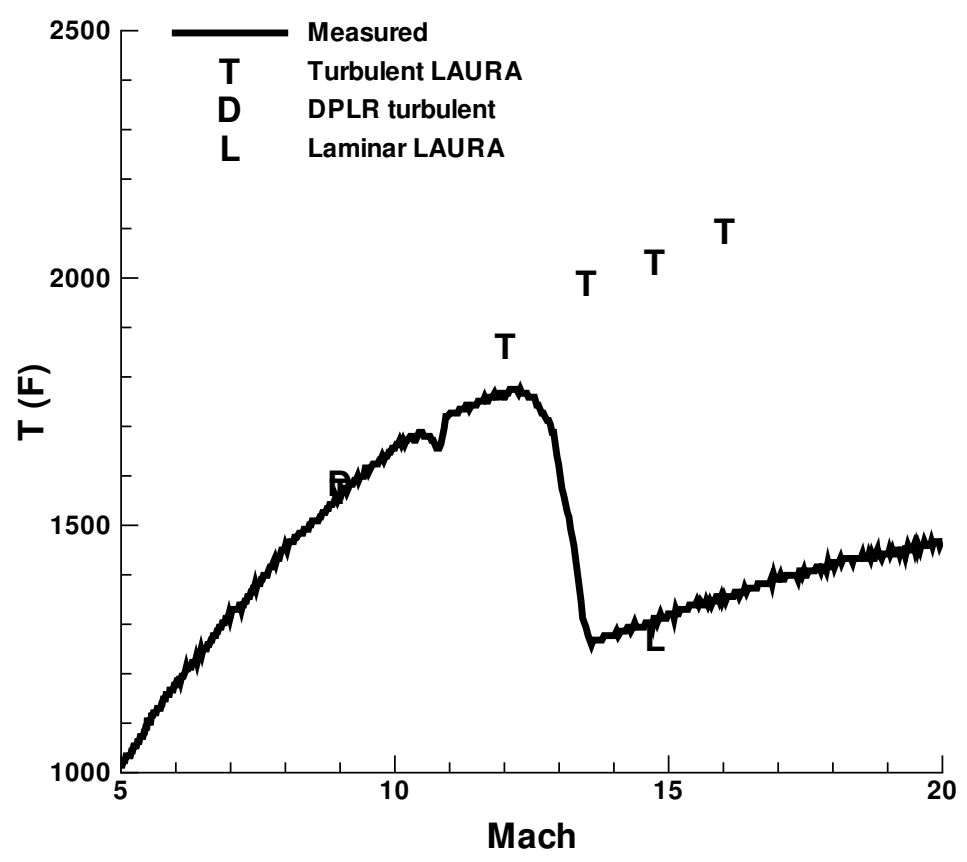

Figure 10. TC-90 temperature history.

numbers less than 11 . The aft thermocouples on STS-128, TC-4, 7, 8a, and 90, that were subject to acreage transition at Mach 13.5 did not exhibit a temperature plateau. TC-6 and TC-80 showed a general leveling off of temperature on STS-128 during the Mach 11-13 range, but not to the extent as was seen for the thermocouples directly behind the boundary layer trip on both STS-119 and STS-128. TC-2 did show a temperature plateau after boundary layer transition that was not reflected in the CFD results, similar to the STS-119 comparisons. So the thermocouples in the wake of the flight experiment trip tend to show a post-transition onset temperature plateau, but the thermocouples subject to general acreage transition do not tend to show a temperature plateau. Possible causes of the temperature plateau are the transient thermal response of the thermal protection tiles, the lack of fully-developed turbulent flow at the Mach 11-15 flight conditions, in interference effect such as vortex shedding from the flight experiment protuberance itself, or a compressibility effect not captured in the CFD turbulence models.

\section{Summary of results}

Surface temperature predictions from turbulent CFD simulations were compared against flight thermocouple measurements from the STS-128 reentry. During that flight, the orbiter Discovery had been fitted with a boundary layer trip installed on the port wing to promote transition at approximately Mach 18, and the remainder of the port acreage of the windward side of the vehicle transitioned to turbulent flow at about Mach 13.5 due to another, unidentified trip forward of the wing area. Seven thermocouples on the windward tiles were judged to be suitable for comparison to turbulent CFD predictions for Mach numbers of 9 and higher. The trends in surface temperature with Mach number from the turbulent CFD simulations matched the measured flight data for Mach numbers less than 11, with the CFD averaging $20^{\circ} \mathrm{F}$ lower than the measurements at Mach 9 for Typical surface temperatures of approximately $1600^{\circ} \mathrm{F} / 870^{\circ} \mathrm{C}$. The temperatures from most of the thermocouples appeared to still be indicative of transitional flow and/or transient thermal response for Mach numbers above 11. One thermocouple in particular, TC-2, which was located directly downstream of the flight experiment trip, exhibited a temperature plateau between Mach 11-15, a plateau not reflected in the CFD results. The cause of this discrepancy between measurement and simulation has not been resolved. 


\section{References}

${ }^{1}$ Anderson, B., "BLT Flight Experiment Overview and In-Situ Measurements," AIAA Paper 2010-240, Jan. 2010.

${ }^{2}$ Wood, W. A., Kleb, W. L., Tang, C. Y., Palmer, G. E., Hyatt, A. J., Wise, A. J., and McCloud, P. L., "Comparison of CFD Predictions with Shuttle Global Flight Thermal Imagery and Discrete Surface Measurements," AIAA Paper 2010-454, Jan. 2010.

${ }^{3}$ Candler, G. V. and Campbell, C. H., "Hypersonic Navier-Stokes Comparisons to Orbiter Flight Data," AIAA Paper 2010-455, Jan. 2010.

${ }^{4}$ Throckmorton, D. A., "Benchmark Determination of Shuttle Orbiter Entry Aerodynamic Heat-Transfer Data," Journal of Spacecraft and Rockets, Vol. 20, No. 3, May 1983, pp. 219-224.

${ }^{5}$ Gnoffo, P. A., Gupta, R. N., and Shinn, J. L., "Conservation Equations and Physical Models for Hypersonic Air Flows in Thermal and Chemical Nonequilibrium," NASA TP 2867, Feb. 1989.

${ }^{6}$ Gnoffo, P. A., "An Upwind-Biased, Point-Implicit Relaxation Algorithm for Viscous, Compressible Perfect-Gas Flows," NASA TP 2953, Feb. 1990.

${ }^{7}$ Wright, M. J., Candler, G. V., and Bose, D., "Data-Parallel Line Relaxation Method for the Navier-Stokes Equations," AIAA Journal, Vol. 36, No. 9, Sept. 1998, pp. 1603-1609.

${ }^{8}$ Stewart, D. A., "Surface Catalysis and Characterization of Proposed Candidate TPS for Access-to-Space Vehicles," NASA TM 112206, 1997.

${ }^{9}$ Reuther, J., Thompson, R., Pulsonetti, M., and Campbell, C., "Computational Aerothermodynamic Analysis for the STS-107 Accident Investigation," AIAA Paper 2004-1384, Jan. 2004.

${ }^{10}$ External Aerothermal Analysis Team, "Smooth Outer Mold Line Aerothermal Solution Database for Orbiter Windside Acreage Environments During Nominal Entry Conditions," Engineering Note EG-SS-06-1, NASA Johnson Space Center, Houston, Texas, April 2005, Presented to Orbiter Configuration Control Board.

${ }^{11}$ Gnoffo, P. A. and Weilmuenster, K. J., "Multiblock Analysis for Shuttle Orbiter Re-Entry Heating from Mach 24 to Mach 12," AIAA Paper 93-2813, July 1993.

${ }^{12}$ Kleb, W. L. and Weilmuenster, K. J., "Characteristics of the Shuttle Orbiter Leeside Flow During a Re-Entry Condition," Journal of Spacecraft and Rockets, Vol. 31, No. 1, Jan. 1994, pp. 8-16.

${ }^{13}$ Weilmuenster, K. J. and Gnoffo, P. A., "Solution Strategy for Three-Dimensional Configurations at Hypersonic Speeds," Journal of Spacecraft and Rockets, Vol. 30, No. 4, July-August 1993, pp. 385-394.

${ }^{14}$ Wood, W. A., Alter, S. J., Palmer, G. E., and Saunders, D. A., "Allowable Trajectory Variations for Space Shuttle Orbiter Entry-Aeroheating CFD," AIAA Paper 2008-6559, Aug. 2008.

${ }^{15}$ Horvath, T. J., Tomek, D. M., Berger, K. T., Zalameda, J. N., Splinter, S. C., and Krasa, P. W., "The HYTHIRM Project: Flight Thermography of the Space Shuttle during Hypersonic Re-entry," AIAA Paper 2010-241, Jan. 2010.

${ }^{16}$ Tang, C. Y., Trumble, K. A., Campbell, C. H., Lessard, V. R., and Wood, W. A., "Numerical Simulations of the Boundary Layer Transition Flight Experiment," AIAA Paper 2010-453, Jan. 2010. 